\title{
Doubly rare: Evelyn Grimberg and Minette van der Ven
}

Steve Chaplin

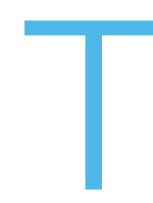

here are many aspects of living with haemophilia that make people feel different from others. But imagine the impact of having a bleeding disorder so rare that you feel different from almost everyone else with a bleeding disorder.

Evelyn Grimberg and Minette van der Ven from The Netherlands are two such people: they have Glanzmann's thrombasthenia, an inherited platelet function disorder. There are perhaps 2,000 3,000 people worldwide living with this diagnosis - a prevalence of about 1 in 4 million population worldwide. However, there are many more cases than expected in some countries - for example, in some areas of Iran, where the prevalence is estimated at 1 in 200,000. Whichever figure is correct, the odds of having two people with Glanzmann's in the same room at random are inconceivably small.

But this is not a random meeting: Evelyn and Minette are close friends who have come together, not because they share this unusual diagnosis, but because they have the same outlook on living with it. And they have also bonded as women who see services for bleeding disorders heavily geared towards boys and men with haemophilia, to the extent that the impact on women with bleeding disorders has been underestimated or ignored.

For Evelyn and Minette, early life with Glanzmann's was similar to that for many of the current generation of adults with a bleeding disorder. Suspicion first arose

STEVE CHAPLIN

Haemnet, UK. Email: steveahaemnet.com

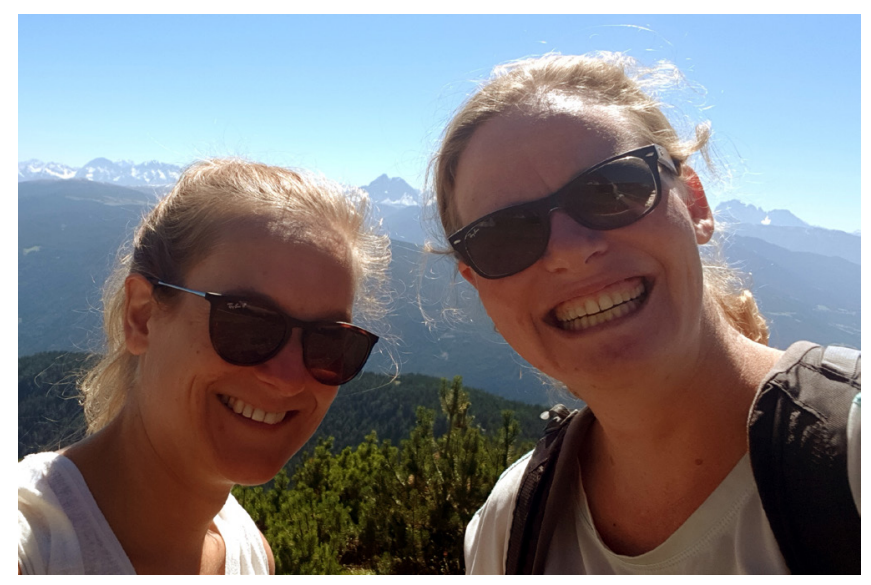

Friends Evelyn Grimberg (left) and Minette van der Ven (right) share a positive outlook on living with the rare bleeding disorder Glanzmann's thrombasthenia. Together, they are active in raising awareness of bleeding disorders in general, and in particular the specific issues faced by women who are haemophilia carriers or have been diagnosed with a bleeding disorder.

after an episode of uncontrolled bleeding - at age four months for Evelyn and two years for Minette. Both are the only family members known to be affected. For their parents, the uncertainty of a future living with a bleeding disorder was compounded by difficulty identifying the cause - it was two years before Minette's diagnosis was confirmed - but both families adopted a robust approach to raising their child.

\footnotetext{
"My parents were very much 'Do what you have to do and take your own risks.' I was quite active because I was always going out and, 'We will see what happens,' and I always came back with bruises and bleeding. But my parents always said, 'You know what? You have to do it. If it's too bad, go back home, your mother and father will be there and we'll help you. But you
} 
have to know your own boundaries, because if you don't learn it you won't know where you have to go.'"

Children with bleeding disorders are special but not different, the women agree. Both were treated the same as their peers:

"... when I got older - I think I was about eight years old - I wanted to play hockey. All my friends did, so I wanted to do that. My sister wanted to do that; she played hockey as well.

My parents were kind of scared about that, but eventually they said, 'Okay, you've got protection on your legs, on your hands, in your mouth - you can give it a try.' And I played hockey for six, maybe eight years."

"I think in your childhood it's very important that your parents help you to deal with your disease, because you're not a patient, you're a daughter or a son. I have a brother and sister and they're completely the same as me."

Both women grew up as a cherished daughter, not a person with Glanzmann's to be protected, and they credit their positive attitude to their upbringing. They do, however, recognise that their parents paid a price for allowing them such freedom. To this day, Minette knows her mother waits apprehensively in case the phone rings with a call for help. Both women still rely on their parents' support, though now they are the ones who recognise when they need help.

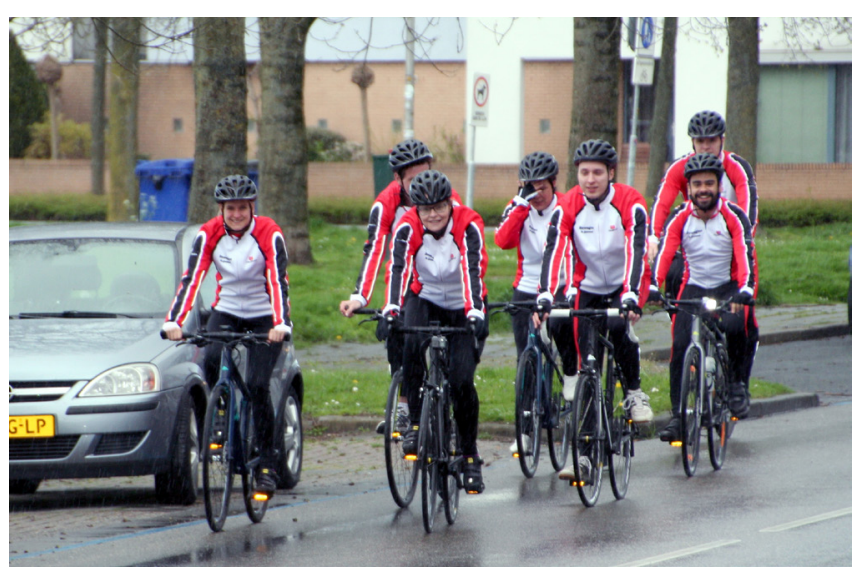

Minette and Evelyn, with their parents' support, were able to enjoy being active during childhood. Today, their awareness raising activities involve physical challenges. Together, they have completed several long-distance bike rides, including a 15-day trip with a team of other cyclists with bleeding disorders from the Netherlands (their home country) to a meeting of the European Haemophilia Consortium in Norway.
"... they know if I call that there is something wrong, because I don't call if I have a little bleed. So, they know exactly that I'll call them if I need them. I think for a parent that's very important, that you know that your daughter or your son knows directly where to go and how to deal with it."

A childhood lived with a bleeding disorder through the 1980s and 1990s was less of a challenge when factor replacement therapy was available but, by contrast with haemophilia, there is no effective prophylaxis for Glanzmann's. Bleeds are treated (with a platelet transfusion, in severe cases), not prevented. For many people, this would be enough to make them avoid the slightest risk - but Evelyn and Minette are not the type to hide away. They have several long distance bike rides behind them, including a $1,000 \mathrm{~km}, 15$-day trip from Utrecht in the Netherlands to Stavanger in Norway for the 2016 European Haemophilia Consortium (EHC) conference.

"... we did it in a group. We want to get more attention about bleeding disorders, so we arranged a group of completely different bleeding disorders... it was also a mixture of women and men, because we thought it very important that all the groups would get the attention they needed."

"Because we are fighting for not only talking about haemophilia, but talking about bleeding disorders. We wanted to cover everything."

As well as raising awareness about bleeding disorders, the project also emphasised the value of being active and physically fit.

"I think for your muscles, for your joints, for your complete body it helps a lot. For me, myself, I have a lot less bruises when I'm more healthy."

"I don't experience a difference in bleeding issues. [Exercise] is not helping me, but of course it's improving my health. You feel better, you sleep better, it's more energetic."

Planning the bike ride took a year, from conception to completion, with monthly plans providing regular goals. Minette says she has a tendency to over-exercise and needed other people to rein in her enthusiasm. The project created a small, supportive group whose members can go on to inspire others. 


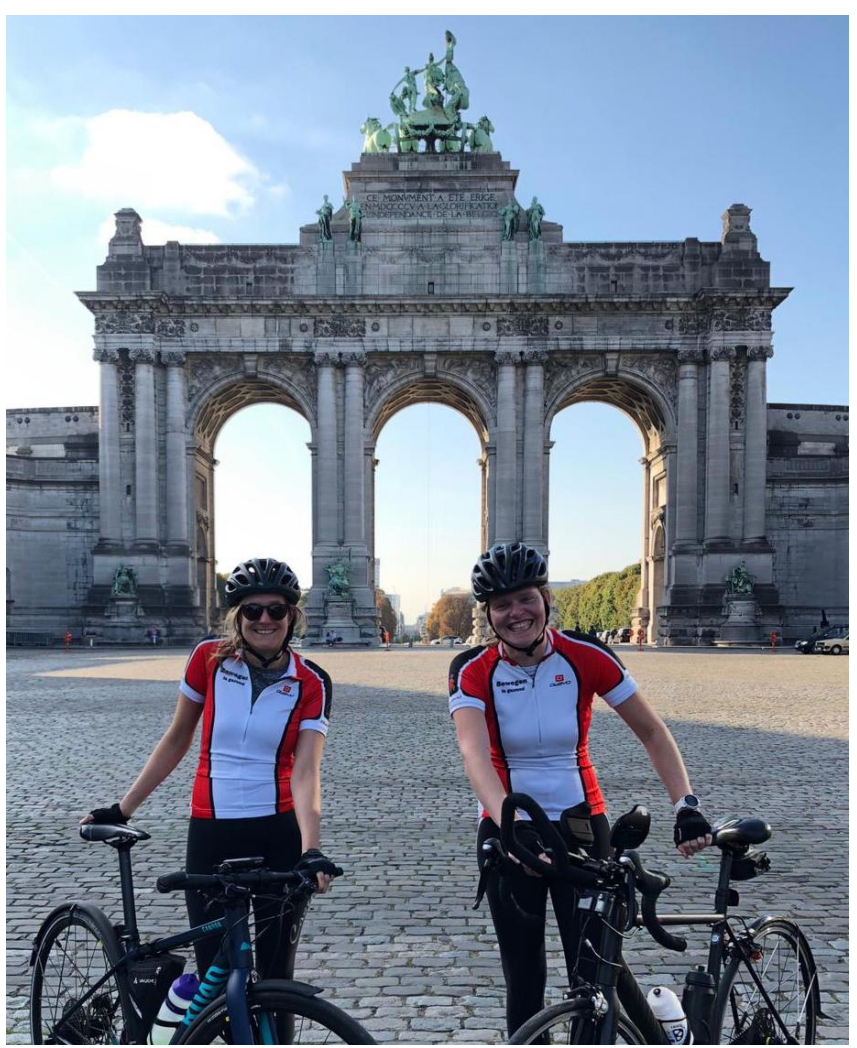

The friends agree that being physically active is beneficial to their general and health and wellbeing, but are aware of the importance of being realistic about their goals and having the support and advice of their healthcare team.

"... doing it together was much more fun.

So, having the community, having people around you where you can do it together and motivate each other is very good as well... Enjoy celebrating the small steps you take because we don't get [to take] big steps."

Having realistic ambitions is especially important for someone with Glanzmann's because the risk of a bleed is ever present. This affects a person's confidence when participating in sports and going on holiday, at any time or place where medical care is not readily accessible. The key to becoming more active is to start small, build up slowly and keep yourself motivated by involving other people. Talk to the medical and nursing team - especially the physiotherapist - but be aware that health professionals are sometimes sceptical about an individual's ambitions.

"... maybe it's difficult to be different, but I am very proud that I'm different. And I think that's what you've got to say, because if I go to my doctor, the first time I go he will say, 'You're completely crazy.' Well, yes, we are. But I think that's one of the first things we do. If there's something else than the normal path, we're always, 'Okay, what are the risks?' But if you can talk with them about what you want to do, I think every doctor or every nurse or every physician, everyone wants to help you to get that goal - but it has to be a reachable goal." "... you have to be realistic. You have to think about what you do in life. I cannot do everything."

Thinking about what can and can't be done affects all aspects of life - even issues as mundane as choosing furniture:

"If we buy a couch or a table, we will not buy a table that has very square corners because we know we get bruised... Sometimes it's a case of, 'Do I like it enough to take the consequences of getting bruises? Yes.' If I really like it, then I'll do it and I know l'll get bruised and have pain for several days and have bruises for two or three weeks. Okay, I'm fine with that. Sometimes I think, 'Okay, no. This is not nice enough - I won't do it.' These are the decisions that I make."

And in truth, bleeding disorders can have effects that reach far beyond the immediate problem of uncontrolled bleeding. For women this is something that has not been properly acknowledged, whether they are told they are a haemophilia carrier or they have a specific diagnosis of a bleeding disorder.

\begin{abstract}
"My first period was quite heavy. I was laying down on my bed because after two or three days I was completely out of energy. And my mother recalls after seven or eight days calling my GP, who came over because I couldn't get out of bed anymore..."
\end{abstract}

"The first one was... extremely bloody, very big clots coming out. And after a week I passed out in the middle of the night and that was a reason for my parents to bring me to the hospital. I needed a blood transfusion."

Evelyn and Minette feel strongly that this is a topic that is not sufficiently aired. Their families had not fully understood how heavy their periods would be and had not realised this was the norm for women with a bleeding disorder: for some it is severe, for others very severe. This lack of awareness was shared by general 
physicians and nurses. Even today, they believe, families are not fully educated about the impact of bleeding disorders on women.

The standard treatment for heavy periods is a hormonal contraceptive, but some women still have breakthrough bleeding and troublesome side effects.

"From 12 to 16 I was on the contraceptive pill, but I had a lot of breakthrough bleeds. I was very bad at handling the hormones. They were very effective on me; it made me quite emotional, crying all the time and I didn't know why, morning sickness like a pregnant woman - it wasn't that good. And I kept having the heavy blood loss and anaemia."

In such cases, the only option is to eliminate periods completely by inducing an early menopause with injections of a progestogen.

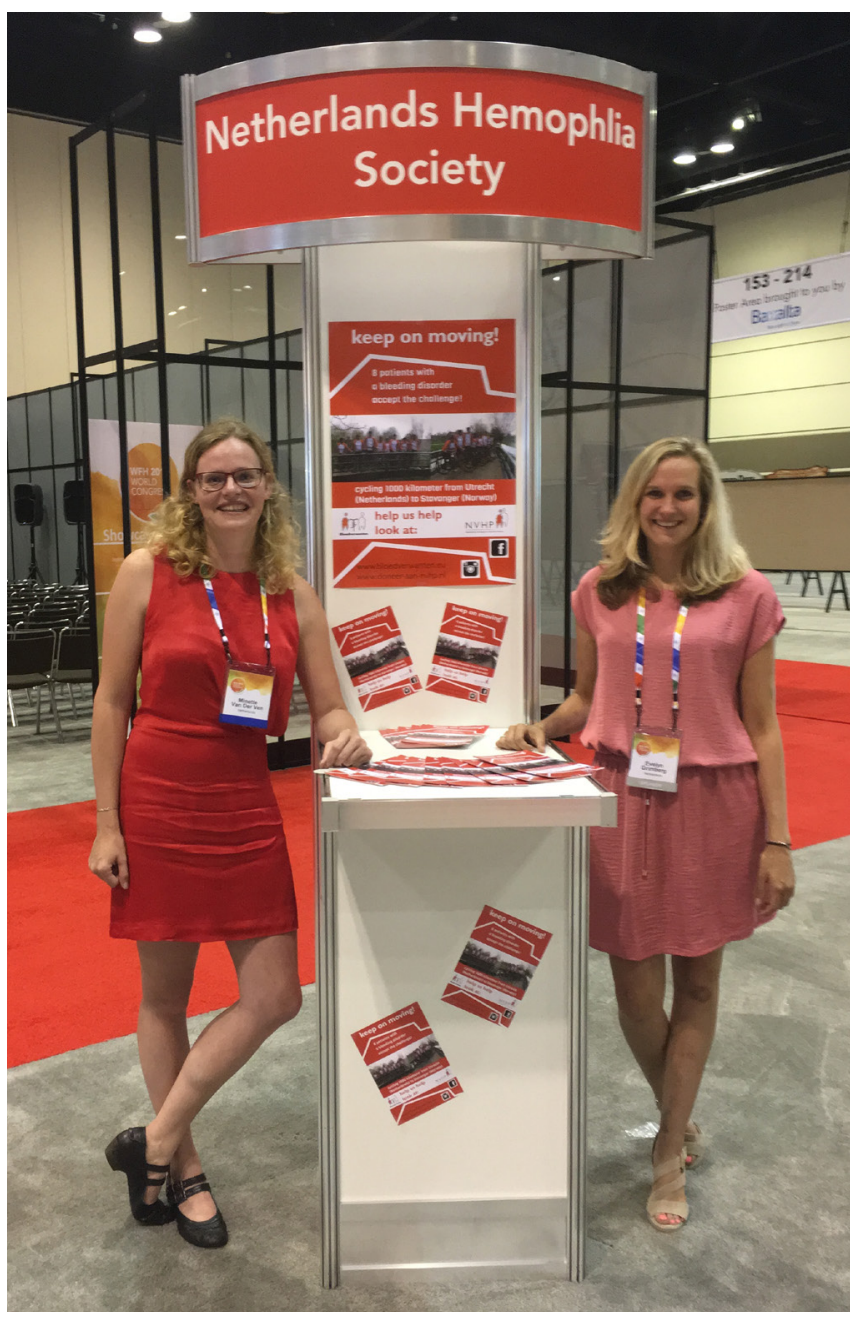

Minette (left) and Evelyn (right) believe that more needs to be done to understand the experiences and impact of bleeding disorders on women who are either carriers or have a diagnosis. Both are involved in the Dutch Association of Haemophilia Patients.
"I haven't had a period since the age of 16 and I've actually got my life back. But on the other hand, the emotional part, the impact that it's having and still is... Always, when I start talking about this part it makes me a little bit emotional."

Both Evelyn and Minette feel that the doctors they consulted had not fully understood the impact of starting periods, and consequently their families were unsure what to expect. Health services need to do a better job of educating parents and girls that what's likely to happen will not be normal. This is not something that girls with bleeding disorders feel able to discuss with their peers at school, so families should be able talk to one another more easily. One idea to help share experiences is to develop an online resource of women's first-hand accounts of living with a bleeding disorder. This applies equally to the women currently diagnosed as haemophilia carriers but who actually have a bleeding disorder themselves.

And once the immediate problem has been managed, there is time to think about the longer term implications:

"... my life is very nice, but also for the future it is having kids, having children - I'm not sure if I can have them because of the damage. When you're 12 years old and you're confronted with the fact that you have a period, this is one thing - even for normal girls, it's big. Having this extreme blood loss is something else. Getting hormones at the age of 12 has so much impact - we don't realise that. We don't talk about it. The doctors just prescribe it, but they don't see the effect."

Evelyn and Minette have a positive outlook on the future for someone born with a bleeding disorder. There will be times when questions have to be answered:

"I think the first thing I would say is that you can be normal as a person with a bleeding disorder... be open about it and don't be scared. You will find out by experience how to deal with it, how to handle it. Don't be scared of that; just let it happen... If you could see me now in my swimsuit you would think, 'Oh my God! What happened to her?' I've got a lot of bruises. And I know my parents got a lot of questions about it and not always nice 
ones - now I get them myself - about abuse. My parents always knew that they had to be open about it and just say what it is - then you see how people respond. I do that. So, if I get questions about it now, 'I have a bleeding disorder. I'm not abused.' Or we can start a conversation - people are interested..."

But their advice for parents could apply equally to every child:

"... take care of the special things the person has, and provide them with the help you can give them. Be there for them and don't make them feel special or different in a negative way..."

\section{ACKNOWLEDGEMENTS}

The assistance of Nanda Uitslager, Nurse Practitioner at the Department of Haematology, Utrecht Medical Center, The Netherlands, is greatly appreciated.

The authors have advised no interests that might be perceived as posing a conflict or bias.

Informed consent has been obtained from the individuals reported in this article.
HOW TO CITE THIS ARTICLE:

Chaplin S. Doubly rare: Evelyn Grimberg and Minette van der Ven. J Haem Pract 2019; 6(1:suppl): S15-S19. https:// doi.org/10.17225/jhp00130.

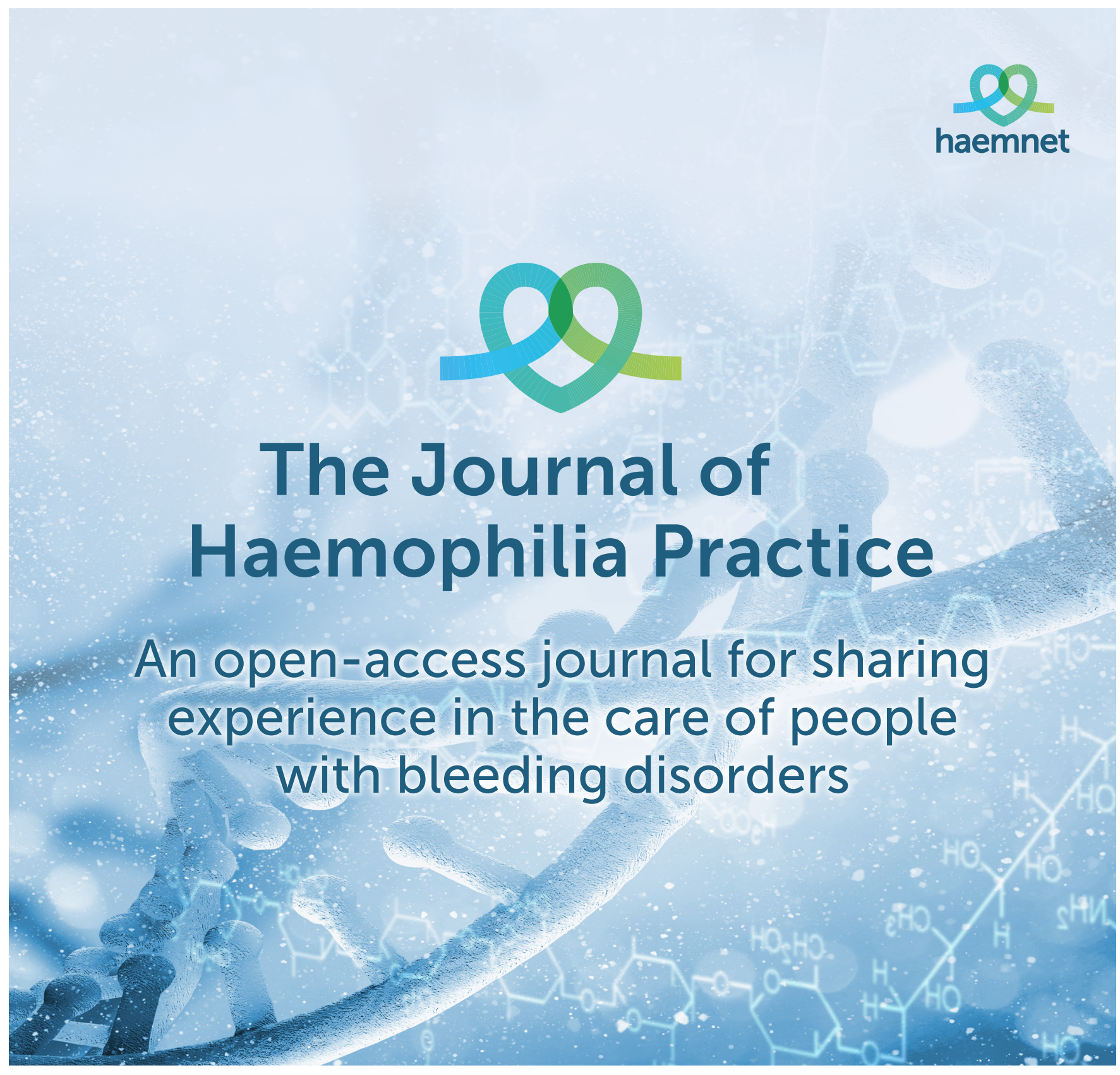

